Agro-Science Journal of Tropical Agriculture, Food, Environment and Extension Volume 16 Number 2 (May 2017) pp. 52 - 58

ISSN 1119-7455

\title{
DETERMINANTS OF ADOPTION OF LAND MANAGEMENT PRACTICES IN KOGI STATE NIGERIA: A GENDER ANALYSIS
}

\author{
Kayode, A.O., Oladipo, F.O. and Daudu, A.K. \\ Department of Agricultural Extension and Rural Development, University of Ilorin, Ilorin, Nigeria \\ Corresponding author's e-mail: toyinkayode2000@yahoo.com
}

\begin{abstract}
The study examined determinants of adoption of land management practices among male and female crop farmers in Kogi State, Nigeria. Multistage sampling technique was employed for the selection of the respondents. Structured questionnaire was used for data collection and analyzed with descriptive and inferential statistics. Data were collected from one hundred and sixty three respondents (163). The mean age of the male respondents was found to be 51 years while that of the female was 44 years. The mean total size land cultivated was 1.1 hectares for male respondents and 0.5 hectares for female respondents while the mean years of schooling for male and female farmers were 11.6 and 11.2 years respectively. Multi variant probit model was used to determine the factors that influence farmers' adoption of the land management practices on their farm. Although the results revealed that farmers age, land size, household size, years of schooling, farming experience and technical know- how were factors that significantly influence land management practices among both genders, It was concluded that years of schooling improve the level of adoption of land management practices among the female farmers while among the male respondents their land size was a critical factor that influence their land management practices.
\end{abstract}

Key words: Gender, Kogi, Land management practices, Level of Adoption, Crop farmers.

\section{INTRODUCTION}

Land is an asset of enormous importance to billions of rural dwellers in the developing world. Right from creation, man depends on land for his basic needs of life. Martin (2010) describes land as a gift of nature to man which remains the most important factor of production. He states that land in its physical form is immoveable but its product however can be moved from one part of the globe to another. The rural dwellers depend on the environment, especially natural resources such as land, for the satisfaction of their basic needs. As land deteriorates in quality, the poor become poorer. It is also a fact that the importance of natural resources, especially land to agriculture and rural development is well recognized. According to Bangladesh, 2001, land can be referred to as the basic natural resource that provides habitat and sustenance for living organisms. However, exploitation of land through practices such as overgrazing, excessive use of fertilizer, soil erosion, soil acidification and over population have greatly affect land productivity. In all parts of Nigeria, there is noticeable evidence of land degradation which varies from place to place in terms of the type, duration, severity, and socio-economic impact (Aruleba, 2004). However one of the most severe constraints to the sustainability of smallholder- based agriculture in sub-Saharan Africa is declining soil fertility. In the past, African farmers managed soil fertility on their farms by fallowing their land. However, as the population increased, fallowing of land reduced, with many farmers adopting intensive land use practices that require fertilizers to replenish nutrients. Declining soil fertility is thus an obstacle for sustainable productivity improvement of crops and consequently livestock. (FAO,2010). Nkonya, et al. (2011) also revealed that the immediate causes of land degradation include biophysical causes and unsustainable land management practices such as deforestation, forest degradation, soil nutrient mining, and cultivation on steep slopes, are also direct contributors to land degradation. In the same vein, Menale (2008) submitted that some major problems of soil productivity in developing countries include population growth, pressure on land, food production practices, land degradation and soil fertility decline, drought, land rights, technology, etc. Considering the aforementioned facts there is therefore the need for holistic and integrated approaches for sustainable land management and soil productivity improvement. On a related note, Abdulazeez et al. (2014) stressed that a common philosophy in sustainable crop management is 
that a "healthy" soil is a key component of sustainability. This implies that a healthy soil will produce healthy crop plants that have optimum vigor and are less susceptible to pests. On the other hand, crop management systems that impair soil quality often result in greater inputs of water, nutrients, pesticides, and/or energy for tillage to maintain yields. In sustainable crop management systems, the land on which the crops are planted is viewed as a fragile and living medium that must be protected and nurtured to ensure its long-term productivity and stability. However, studies by Marshall (2004) and Rezvanfar et al. (2009) have shown that the adoption of land management practices is multidimensional with numerous factors such as age, educational background, household size and farm size affects the willingness of farmers to use various conservation practices. In spite of the numerous significance of land to humanity FAO (2002) affirmed that cultural, sociological and socioeconomic factors strengthen the bias of policies in land access and tenure to have favored a particular gender. Kayode (2013) also observed that conservation and management practices of natural resources such as land must be promoted among both genders because of their vital roles in the agricultural sector and for agricultural growth to fulfill its potential, gender disparities must be addressed and effectively reduced. The pattern of land acquisition and the land management practices adopted by farmers (either male or female) are key factors to agricultural and land management practices.

Bortei-Doku (2002) notes that one important traditional channel for woman to own land is the transfer of land as gifts from families or spouses. It is also worth noting that civil law entitles women to have access to land, but certain customary laws stipulate that only men have the right to own land this has been a barrier to effective land management practice in the developing countries. Considering the concept surrounding gender issues in pattern of land acquisition which influences land management practices and for the fact that gender cut across all areas in agricultural sector, it is therefore imperative to look beyond physical and biological difference between males and females as they are both important factors in agricultural production and their activities cannot be underestimated if the nation is to experience a sustainable agricultural production.

Based on the above background, the objectives of the study were to:

(1) Describe the socio-economic characteristics of the respondents

(2) Ascertain the patterns of land acquisition among the respondents; and

(3) examine the level of adoption of land management practices

\section{Hypothesis}

Ho. There is no significant relationship between factors influencing land management practices and the level of adoption of land management practices.

\section{MATERIALS AND METHODS}

The study was carried out in Kogi state, Nigeria. The state which is located on longitude $6.45^{\circ} \mathrm{E}$ and latitude $7.49^{\circ} \mathrm{N}$, is in the North-central zone of Nigeria. It has a land area of 28,313.5 square kilometres and a projected population of 3,278,48 (National Population Commission, 2006). It is popularly called the Confluence state because the confluence of River Niger and River Benue is at its capital, Lokoja. It shares common boundaries with Niger, Kwara, Nassarawa and The Federal Capital Territory to the north. To the east, the state is bounded by Benue and Enugu States, to the south by Enugu and Anambra States, and to the west by Ondo, Ekiti and Edo States. There are three main ethnic groups in Kogi: Igala, Ebira, and Okun; with the Igalas being the largest ethnic group in the state. Lokoja, the Niger/Benue confluence town is the state capital. Kogi State occupies 29,833 square kilometres. There are twenty-one Local Government Areas in the state. Agriculture is the mainstay of the economy (Alabi, 2006). There are many farm produce from the state notably coffee, cocoa, palm oil, cashew, groundnut, maize, cassava, yam, rice, melon, soyabean, cocoyam etc. The population of the study were male and female registered crop farmers. Multi-stage sampling technique was used for sample selection. The first stage involved randomly selection of twenty percent of the twenty one local government areas (LGA) in the state making four LGA (Ijummu, Kaba- bunnu, Yagba East and Mopa LG). In the second stage, from the number of registered farmers by extension agents in each LGA 0.5 percent were selected using systematic sampling procedure. Efforts to get equal number of both male and female respondent proved abortive due to the fact that from the list of registered farmers gotten from the four local government, the numbers of male and female farmers were not equal (i.e. A total of 18,050 males and 14,570 females were registered). Only 0.5 percent was selected due to the large numbers of registered farmers within the LGA, making a number of 90 males and 73 females which gave a total number of one hundred and sixty three respondents (163). Descriptive statistics was used to describe the socio-economic characteristics of the respondents and their pattern of land acquisition. A four point rating scale was employed to measure the respondents level of adoption of land management practices; respondents were asked to tick the best option that describes the land management practices they adopted and were rated as follows; used very often $=4$ used often, $=3$ discarded $=2$ and not used at all. $=1$ after which the mean score and standard deviation was 
Kayode, A.O. Oladipo, F.O. and Daudu, A.K.

calculated for the land management practices for both sex in order to show their level of adoption of the land management practices. Any score below the mean score were categorized as low adopters, scores within the mean score were medium adopters while those above the mean scores were categorized as high adopters (i.e. $\bar{X}-\bar{X}_{+1 \mathrm{SD}}$ where the mean score for male respondent $=41.3, \mathrm{SD}=4.7$ and the mean score for female respondents $=34.1, \mathrm{~S} . \mathrm{D}=4.2$ see table 4 ). Multivariate probit model was used to determine factors influencing the choice of their land management practices.

\section{Empirical model of the multivariate probit model}

The multivariate probit is a generalization of the probit model used to estimate several correlated binary outcomes jointly and is generally specified as;

$$
\mathrm{Y}_{1}=\beta \mathrm{x}_{1}+\varepsilon_{1} \ldots \ldots \ldots \text { (1) }
$$

Where $Y_{1}$ are the underlying latent variables that index the land management options on a given plot of land, $\mathrm{x}_{1}$ is a $(\mathrm{kx} 1)$ vector of explanatory ariables, $\beta$ is a $(\mathrm{kx} 1)$ vector of the parameters to be estimated, and $\varepsilon 1$ is the stochastic error term. The empirical model that was used to estimate the factors that influence the adoption of farmers land management practices is specified as follows;

Where;

$$
y=\alpha+\beta 1 \times 1+\beta 2 \times 2+\ldots+\beta 5 \times 5+e \ldots .(2)
$$

$\mathrm{y}=$ Land management practice (Bush fallowing, planting of cover crops, mixed cropping, mulching and tree planting)

$\mathrm{x} 1$ = Age of respondent (years)

$\mathrm{x} 2=$ Total land cultivated (hectares)

$\mathrm{x} 3==$ Education of the farmer (years of schooling)

$\mathrm{x} 4=$ Farming experience (Years)

x5 =Technical know- how (Good (1), Poor (0)

$\mathrm{e}$ is the random error term, and $\beta 1$ to $\beta 5$ are the

coefficients to be estimated.

\section{RESULTS AND DISCUSSION \\ Socio-economic Characteristics of the Respondents}

The average age of male respondents was 51 years while that of female respondents was 44 years. The implication of this result is that female respondents were younger in age than their male counterparts probably because females marry at a very younger age which indicated that they are in their active age and can be more economically productive in their farming activities and other source of livelihood. About $89.1 \%$ and $73.1 \%$ of the male and female respondents were married, respectively. The mean years of schooling for male are 11.6 while female respondents had 11.2 years which is an indication that the respondents are literates at various levels. This result is in line with the work of Adetunji and Raufu (2012) in their work in SouthWestern Nigeria, which states that larger percentage of respondents acquired secondary education. The mean total number of cultivated land for male and female respondents was 1.1 and 0.5 hectares of land respectively which implies that both men and women are small scale farmers practicing on small acreage of land. Farming experience of male was 25 years and female 14 years. This indicates that male respondents had longer years of farming experience than their female counterparts. This may be due to the fact that many of the women may not have been engaged in farming before marriage but found themselves in it as they have to assist their husbands in whatever enterprises they are doing. (See Table 1).

\section{Pattern of Land Acquisition among Respondents}

Table 2 shows that majority $(90.2 \%)$ of the male respondents secured land through inheritance followed by 34.1 percent who have access to land through land tenancy at will of government and also 31.7 percent who purchased land About 74.4 percent of the female respondents had access to family land (i.e. husband and wife), 35.4 percent secured their land through inheritance while14.6 percent purchased lands. This implies that both male and female respondents have access to land through various means but men seems to have more access to land than women. It was noted that in Kogi State, most women especially among the "Okuns" claimed they acquire land through inheritance i.e. they inherit land as female but not as equal as their male counterparts. This result confirms with CEDAW (2003) who reported that Nigerian women have very limited land acquisition rights. Civil law entitles women to have access to land, but certain customary laws stipulate that only men have the right to own land. In practice, women can acquire land solely through marriage or family.

\section{*Multiple responses}

Land Management Practices Adopted by Respondents. The data in Table 3 shows the distribution of respondents by land management practices adopted by the respondents. Eighty seven percent of the respondents practiced mulching. This is followed by mixed cropping with 79.5 percent. Next is tree planting (70.9), shifting cultivation (69.7) while planting of cover crops and bush fallowing has 67.7 percent each. This finding indicates that most of the male respondents in the study area have vast knowledge of the land management practices and exploit different management practices to improve their agricultural productivity, A hundred percent of the female respondents practiced mixed cropping, followed by mulching with 97.2 percent. Other practices follow this order: crop rotation $(69.8 \%)$, tree planting $(23.3 \%)$, and bush fallow (13.6\%). It was noted that land management practices such as bush fallowing and 
Determinants of Adoption of Land Management Practices in Kogi State

shifting cultivation have higher percentage among the male respondents while they have lower percentage among female respondents. This is an indication that male respondents were more involved in the practices that allow them to abandon a place for some time before returning to it later because they have more access to land, but women were not opportune to do such. Hence, they practiced land management that will allow them to cultivate for a longer period on a piece of land. This result is in agreement with the report of Cheryl et al. (2009) which submits that the channel through which people acquire land determines the type of land management being practiced on such land.

Table 1: Distribution of respondents by socio-economic characteristics

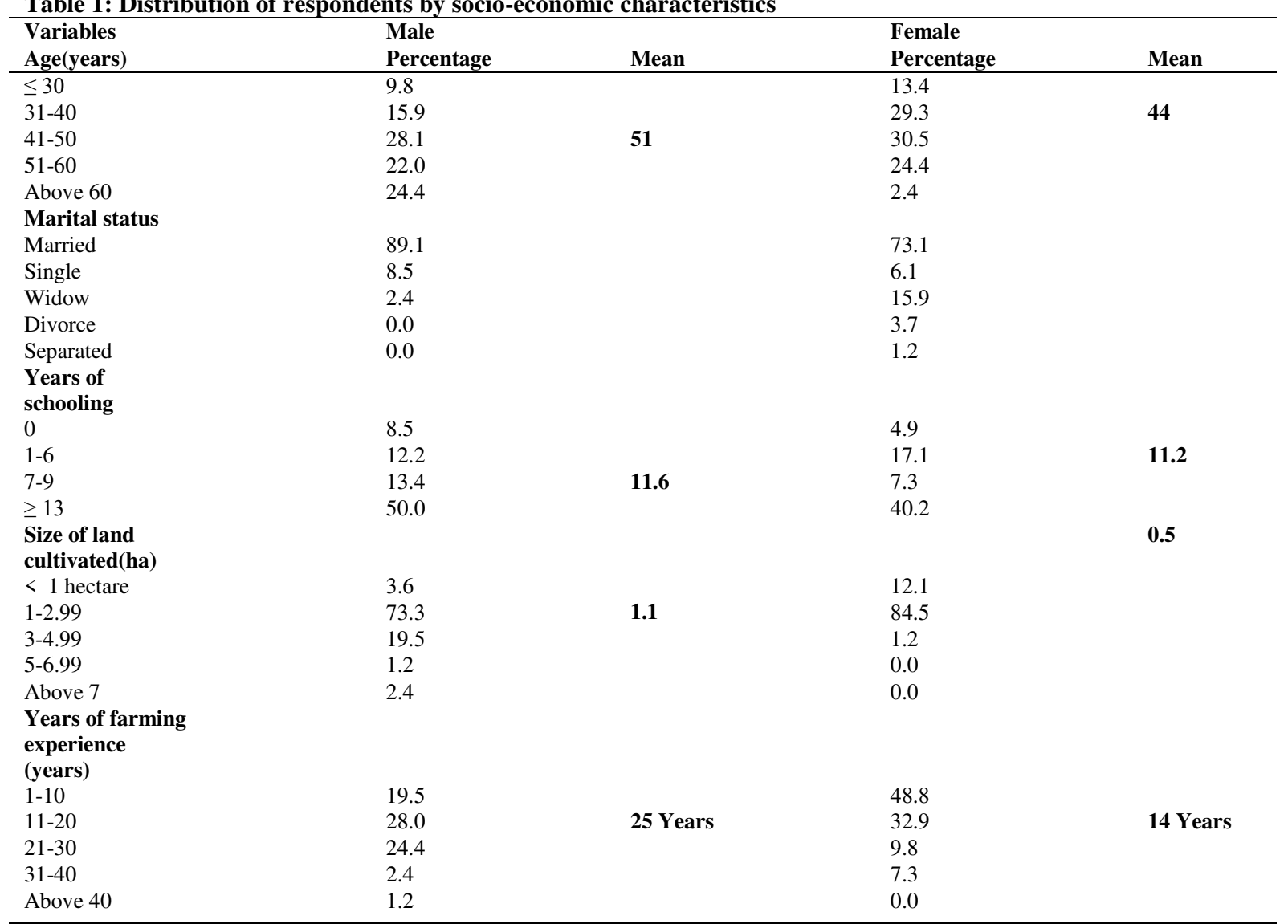

Source: Field survey, 2015

Pattern of Land Acquisition among Respondents

Table 2: Land acquisition pattern.

\begin{tabular}{lll}
\hline *Land Acquisition Pattern & Male (\%) & Female \\
\hline & & $(\%)$ \\
Purchased land & 31.7 & 14.6 \\
Inherited land & 90.2 & 35.4 \\
Rented land & 13.4 & 57.9 \\
Family land(Husband and wife) & 24.4 & 74.4 \\
Lease land & 18.3 & 11.0 \\
Land tenant at the will of & 34.1 & 7.3 \\
government & & \\
Gift from community & 6.1 & 2.4 \\
Gift from friends/relatives & 8.5 & 1.2 \\
\hline Source: Fild survey, 2015 & &
\end{tabular}

Source: Field survey, 2015

*Multiple responses
Table 3: Distribution of Respondents by Land Management Practices in Kogi State $\mathrm{N}=163$

\begin{tabular}{lcl}
\hline *Land Management Practices & Male & Female (\%) \\
\hline & $\mathbf{( \% )}$ & \\
Shifting cultivation & 69.7 & 34.4 \\
Crop rotation & 44.0 & 69.8 \\
Mixed cropping & 79.5 & 100 \\
Planting of cover crops & 67.7 & 89.0 \\
Bush fallowing & 67.7 & 13.6 \\
Mulching & 87.0 & 97.2 \\
Tree planting & 70.9 & 23.3 \\
Chemical fertilizer application & 59.1 & 73.9 \\
Zero tilling farming & 6.4 & 0.0 \\
The use of irrigation & 7.5 & 1.4 \\
\hline
\end{tabular}

Source: Field survey, 2015

*Multiple responses 
Kayode, A.O. Oladipo, F.O. and Daudu, A.K.

\section{Level of adoption of land management practices by respondents within the study area}

Table 3 revealed that $64.4 \%$ and $53.4 \%$ of the male and female respondents, respectively were in the category of those that adopt land management practice at a moderate level while $21.2 \%$ and $17.8 \%$ of the male and female respondents, respectively belong to the high adoption category of land management practice and $14.4 \%$ and $28.8 \%$ of the male and female respondents respectively are low adopters of land management practices. This result implies that majority of the respondents were in the medium level of land management practices adopters. This could be probably because of their means of acquiring land which they claim is by inheritance for the male respondents and cultivating on family land for the female respondents (Table 2). This means of acquiring land has to do with excessive fragmentation which may not give room for an adequate land management practice.

\section{Determinant of Adoption of Land Management Practices.}

The estimates of the determinants of adoption of land management practices for each separate category were given in Table 5 .

\section{Bush Fallowing model}

The adoption of bush fallowing practice among the male farmers is influence positively by age of the farmer, land size and years of schooling. The positive relationship indicates that a unit increase in both of either age, land size and years of schooling of the respondents will likely determine the adoption of bush fallowing practices among the male farmers while among the female farmers this practice is been influenced positively by their age and farming experience in the study area. This implies that the older the farmers are the more land the farmers own, the more likely they adopt bush fallow practice.

\section{Planting of cover crops Model}

Planting of cover crops on the farmers plot is positively associated with the age and land size of the male farmers while the more years spent in school by the female farmers, the more likely the farmers may decide to plant cover crops this may be because of the knowledge they have acquired on planting of cover crops that it increase fertility and crop yields.

\section{Mixed cropping model}

The farmers' choice to adopt mixed cropping on the plot was found to be significantly related with the technical know-how among the male respondents while age, land size and years spent in school may positively be associated with the adoption of this practice among the female farmers. This is an indication that the farmers make use of the available land to maximize their output so their involvement in mixed cropping is high. Also the more technical knowledge of the land management practices by the farmers, the more likely they adopt mixed cropping model since it involves more than one crop on a piece of land, Care must be taken to adopt land management practices that will accommodate all the types of crops on the land.

\section{Mulching Model}

The use of mulching on the farmers plot is positively associated with age. The implication of this result is that an increase in the age of respondents will likely increase the use of mulching, hence while the older farmers adopt mulching, the younger farmers will likely adopt other innovative. Similar findings have been reported by Abdulazeez (2014) that younger farmers are more innovative and better adopters than older farmers besides, preference for such practice may be due to the fact that it will reduce drudgery associated with highly labor intensive practices.

Table 4: Categorization of adopters of land management practices in Kogi State

\begin{tabular}{|c|c|c|c|c|}
\hline Category of adopters & Male & & Female & \\
\hline & Scores & Percentage & Scores & Percentage \\
\hline Low adopters & $(\bar{X}-$ ISD $)<35$ & 14.4 & $(\bar{X}-$ ISD $)<31$ & 28.8 \\
\hline Medium Adopters & ( $\bar{X}$ to $\bar{X}+$ ISD) $36-46$ & 64.4 & ( $\bar{X}$ to $\bar{X}+$ ISD) $32-40$ & 53.4 \\
\hline High adopters & $(>\bar{X}$ to $\bar{X}+$ ISD) $>46$ & 21.2 & (> $\bar{X}$ to $\bar{X}+$ ISD) $>40$ & 17.8 \\
\hline Total & & 100 & & 100 \\
\hline
\end{tabular}


Determinants of Adoption of Land Management Practices in Kogi State

Table 5: Multivariate Probit Model Showing Significant Relationship between Some selected factors Influencing Land Management

Practices and Adoption of some selected land management practic

\begin{tabular}{|c|c|c|c|c|c|c|c|c|c|c|}
\hline \multirow[t]{2}{*}{ Variables } & Bush fallowing & \multicolumn{2}{|c|}{ Planting of cover crops } & \multicolumn{2}{|c|}{ Mixed cropping } & \multicolumn{2}{|c|}{ Mulching } & \multicolumn{2}{|c|}{ Tree planting } & \\
\hline & (M) & (M) & (F) & (M) & (F) & (M) & (F) & (M) & (F) & \\
\hline Constant & $.008(0.958)$ & $.169(0.215)$ & $1.053(0.00)$ & $76(.000)$ & $.975(.000)$ & $.9998(.00)$ & $.733(.000)$ & $.64366(.00)$ & $.411(.009)$ & $.1132(.511)$ \\
\hline Age & $.009(0.001)^{* *}$ & $0056(0.09)^{*}$ & $005(0.02)^{* *}$ & $22(0.554)$ & $-.003(.208)$ & $.0518(0.09) *$ & $.004(.06$ & $.00499(.35)$ & $.005(.127)$ & 373) \\
\hline Land size & $.007(0.06)^{*}$ & $279(.092)$ & $-.004(0.08)^{*}$ & $22(.508)$ & $-.027(.010)$ & $.0256(.003) * *$ & $-020(.040)$ & $.03666(.100)$ & $.022(0.08)^{*}$ & $-.0023(.913)$ \\
\hline Years & $.064(0.03) * *$ & $39(0.0$ & 261(0.174). & $4(.0 .06)^{*}$. & & $.004)^{* * *}$ & -.0 & $.014(.344)$ & $3 .(154)$ & 183) \\
\hline Farming experience & $-.004(0.926)$ & $.0094(.006) *$ & $.024(0.547)$ & $.0037(.322)$ & $.001(.627)$ & $.00088(.331)$ & $-.001(-.042)$ & $.004888(.296)$ & $-.002(.607)$ & $.0141(.001)^{* * *}$ \\
\hline Tech. know-how & $-.039(0.356)$ & $.009(.770)$ & $-.039(0.356)$ & $.0225(.522)$ & $.063(.040)^{* *}$ & $-.00114(892)$ & $.019(.498)$ & $-.01018(.815)$ & $.053(.163)$ & $.037(.361)$ \\
\hline
\end{tabular}

Field survey, $2015 ; *$ Significant at $10 \%, * *$ Significant at $5 \%$ 
Kayode, A.O. Oladipo, F.O. and Daudu, A.K.

\section{Tree planting model}

The farmers' decision to adopt afforestation (i.e. deliberate planting of trees) on the plot is significantly related to the land size of the respondents. The implication is that an increase in the plots of land, may likely determine the deliberate planting of trees. Since there will be more land for planting of tress. Also among the female respondents, tree planting is positively associated with their farming experience which implies that the older they are in farming activities the vast knowledge they have on the importance of trees which makes them plant trees on their little available land.

\section{CONCLUSION AND RECOMMENDATION}

This study concludes that age, land size, years of schooling, farming experience and technical know how are prominent factors in the choice of land management practices among male and female crop farmers. The findings of the study show that both male and female farmers are in the medium category of adopters of land management practices. It is therefore recommended that more sensitization on the relevance of land management practices is still needed among male and female crop farmers to encourage the increase of adoption of land management practices which will increase the soil fertility and this will boost food production and also the issue of gender inequality should be attended to by educating both gender right from childhood so that each gender will be given equal opportunity to survive and have equity towards production resources since both of them are important factors in Agricultural production.

\section{REFERENCES}

Abdulazeez, M.L, Omotesho, K. F, Adekola, O. F and Adekunle, D: (2014) Assessment of Land Management Practices in Food Crops Production among Small Scale Farmers in Kwara State, Nigeria International Journal of Agricultural Management and Development (IJAMAD)
Adetunji M.O and Raufu M.O. (2012); Determinant of Land Management Practices among Crop Farmers in South-Western Nigeria. Global Journal GJSFR 12 (1): 9-14.

Aruleba, J.O (2004): Influence of Cropping System, Land Type and Sustainability of Land Degradation in South Western, Nigeria. A Ph.D. Thesis of University of Ibadan, pp 244

Bangladesh, C.A, (2001): Erosion and soil productivity in Africa. Journal of Soil and Water Conservation, 45(3): 431-436.

CEDAW (2003), Consideration of Reports Submitted by States Parties under Article 18 of the Convention on the Elimination of All Forms of Discrimination against Women: Nigeria, Change, vol. 3 Nos 1 \& 2, January and April, $67-112$.

Cheryl D, Camel E and Caren L (2009): Gender Analysis Pathway Out of Poverty Paper Present At the IFAD FAO-ILO Workshop. On gaps, trends and current Research in Gender Dimension of Agricultural and Rural Employment Rome 31 March - 2 April 2009.

Food and Agricultural Organization, (2010). "ClimateSmart "Agriculture; Policies, Practices and Financing for Food Security, Adaptation and Mitigation. FAO, Rome.

Kayode AO, Okunade EO and Uzokwu UN (2013). “ Gender Access to productive Assets of farm land among crop farmers in Kwara state, Nigeria" . World rural observations 2013;5 Published by Marsland Press, PO Box 180432, Richmond Hill, New York 11418, USA.

Martin-Dada(2010) Nigeria land reforms -the lingering debate an article in the daily independence http://www.independentngonline.com/1stJan2010

Maureen Z, Mukata W and Johnny M (2011): SocioEconomic Analysis Of Land Management Practices In The Agricultural Highlands Of Uganda: A Case Of Kabale Highlands Research Report Series Issn 08569681 Vol. I Issue No.5.

Menale, K. Z., J. Pender and G. Köhlin, (2008): "Sustainable Agricultural Practices and Agricultural Productivity in Ethiopia: Does Agroecology Matter?" RFF and Environment for Development Initiative Working Paper, Addis Ababa, Ethiopia.

Nkonya, E., Nicolas, G. Joachin, V.B and Alex D.P. (2011): Economics of Land Degradation in South Asia. International Food Policy Research Institute (IFPRI), Issue 68: 56-72. 